\title{
MATERIA DE DESAPROPRIAÇÃO
}

\section{RAZÕES DE APPELLAÇÃO \\ EM PROL DOS EXPROPRIADOS}

PELO ADVOGADO

Raphael Corrêa

\section{Egregio Tribunal}

Si é licito comparar as grandes coisas com as pequenas, os autos que temos em mãos é um chaos, que Ovidio explica ser rudis indigestaque moles: é grosseira e indigesta mole.

Para que não deixasse de ser chaos desde seu primeiro nascedouro, começou a Camara Municipal errando na enunciação do seu direito de desapropriar. Como se lê á fl. ella disse que ficam declarados de utilidade publica para serem desapropriados.

E' disparate. Não ha dois graos no direito de nosso Estado e de nossos municipios quando exercitam o soberano direito de desapropriar.

Dois graos tinha a lei do Municipio Neutro, onde, declarada a utilidade publica de uma propriedade, o proprietario podia recorrèr desse acto ao ministro do Imperio. Si não obtinha provimento, então a Camara expropriante decretava a desapropriação. O primeiro acto, bem se vê, não era ainda o acto expropriante; este segundo sim.

Para nós, auctorisadas as Provincias, por força do Acto Addicional fez a nossa assembléa provincial 
de 1836 a lei n. ${ }^{\circ} 57$ de 18 de Março, a qual é o assento da materia, tanto da desapropriação, como da respectiva indemnisação.

Pela nossa lei, pois, não ha dois graos: dizer é doclarada de utilidade publica tal propriedade é o mesmo que dizer fica desapropriada a propriedade tal. O disparate, porém, da Camara de Botucatú não é de admirar, porque na de S. Paulo, onde assentam conselheiros, barões, bachareis, doctores e altas patentes da guarda nacional, todos os dias se lê o mesmissimo erro.

Um segundo erro commetteu a Camara de Botucatú e da especie em que se costuma dizer-levar o carro adiante dos bois. Porque, si havia de assignalar primeiro o terreno para depois desaproprial-o, não o fez. Primeiro desapropriou no vago; depois é que mandou medir a area sobre que devia radicar-se a expropriação.

Com quanto muito omissos o mappa e o relatorio, que junctou o procurador da Camara instruindo a sua petição inicial, todavia alguma luz trazem ao chaos. No que muito se deve reparar é na indecente linguagem em que está escripto o relatorio. Que haja brasileiro que mande fazer por extrangeiros boçaes um serviço tão singelo de agrimensura, como é o levantamento do perimetro desapropriado, comprehende-se; que haja brasileiro que por preguiça de copiar e passar para o portuguez o que escreveu em algaravia mascavada o extrangeiro audaz, isso a gente acredita quando vê, maxime sendo papel destinado desde logo a toda publicidade. Não faria nada de mais o Meritissimo Juiz da primeira instancia si mandasse primeiro traduzir aquillo para depois ser junctado aos autos. 


\section{Erros do procurador}

Si o mappa e o relatorio não esclarecem á evidencia, a petição, no item $33^{\circ}$, affirma categoricamente que a area desapropriada contém duas glebas distinctas, consideradas quanto á pertenção dellas. Uma, a menor, calculada em 53 alqueires, pertence ao Commendador Ferreira; o resto que é a maior, orçada em 186 alqueires, pertence a uma fazenda commum. Paremos aqui por um momento.

$$
\text { ** } *
$$

Esquecia-nos dizer que, antes do chaos ou confusão das glebas, o procurador da Camara commetteu um erro, que se perpetuou nos autos desde o rosto delles até final. Foi chamar a isto--processo de desapropriação.

Não se tracta nesta papelada confusa de desapropriar, porque a desapropriação é operada pelo só acto da Camara, quando declara soberanamente de utilidade publica a propriedade individual.

Em 7 de Junho do anno passado, conforme a certidão de fl. 4 , foi decretada e ficou feita a desapropriação. Tudo mais que dahi se segue é processo de indemnisação. A indemnisação se processa, porque ella não se póde operar sinão por uma série de actos. Mas a desapropriação nunca. Esta desattenção nas minimas coisas revela a desidia ou ao menos a falta de exacção no cumprimento do dever.

Tanto custa dizer certo como falar errado. Porque, pois, não usar das palavras segundo o conceito juridico que ellas encerram e commetter um disparate de tão elementar emenda?

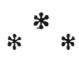


Voltemos a tomar o fio quebrado de nossas duas glebas. Vinhamos dizendo que a menor gleba é do Commendador Ferreira, e que a maior faz parte de um predio commum.

Não sabemos si ignorancia simploria ou manha da Camara no dizer a pertenção das glebas. Ella não diz que a gleba maior pertence a Candido Bernardes Villas-Boas com seus ftlhos, mas diz que é uma gleba que está em commum.

Si a Camara quiz dizer que a maior gleba está em commum, porque na verdade faz parte de um predio indiviso, disse coisa verdadeira, mas não disse a verdade por inteiro. Nos predios communs ou indivisos a regra é que os communheiros possuem ou tem seus sitios pro diviso. E Bernardes Villas-Boas com seus filhos possuiam e tinham a sua gleba pro diviso, o que quer dizer que no exercicio da posse e direitos dominicaes excluiam dali quaesquer outros compartes da fazenda Rio Claro.

Ora, si era Villas-Boas com seus filhos o occupante da maior gleba, porque não o disse a Camara?! Adivinhem os Paduanos.

$$
*^{*} *
$$

A este ponto faz uma breve explanação inexcu. savel sobre o direito soberano de desapropriar, quando recae sobre predios indivisos. Esse direito supremo, preeminente ao mais forte direito que possa ter o individuo, exercita-se sobre os predios divididos, como sobre os indivisos; corta e retalha uma ou duas dessas unidades agrarias, a que chamamos sitios ou fazendas; para elle não ha cercas artificiaes ou vedos naturaes, pelos quaes costumam os proprietarios assignalar as 


\section{$-31-$}

lindes de seus dominios; o seu unico limite é a necessidade ou utilidade publica reconhecida pelo poder expropriante.

Assim nas grandes desapropriações que tem feito o governo do Estado para abastecer de agua potavel esta Capital, e para falar só na ultima, elle desapropriou parte de um sitio chamado Gonçalo, parte de Piracaia, parte de Barrocada, parte dos Paulos.

Numa palavra: o governo examinou o CABUÇú e seus affluentes; achou necessario desapropriar uma tal e determinada area que abarcasse todas as nascentes e mandou fazer o perimetro. Feito este, é que se vio que de alguns predios a area desapropriada apanhou talvez metade, de outro um terço, de outro um quinto ou ainda menos. Nada ha que dizer, nada houve que reclamar. Todos aquelles proprietarios, até o mais minimo delles, que foram encontrados dentro do solo expropriado, todos tem tido o seu pagamento segundo o valor das terras que occupavam e das bemfeitorias, que foram obrigados a abandonar.

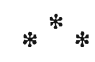

Para o poder publico expropriante nada monta que o solo que desapropria seja de um predio dividido ou de um predio indiviso. Elle desapropria e acto continuo convida o proprietario a tractar a in. demnisação. Proprietario é o occupante da terra que tem titulo de dominio ou o dono da bemfeitoria sem terra : com esse e só com esse tem que se entender o poder publico, porque esse é que vai ser e é privado de seu patrimonio.

Si por acaso a desapropriação recae sobre um solo inoccupado, cujo dominio não conste, não ha a 
menor difficuldade, porque processa-se a indemnisação judicialmente com um curador que representará o incerto proprietario e o valor da indemnisação ficará em deposito.

Mas, só porque Bernardes Villas.Boas é communheiro da fazenda Rio Pardo, pedir a citação de gregos e troianos, a titulo de compartes desse predio, isso é o mais exotico disparate, que só podia occorrer a quem não tem o dom de primeiro pensar para depois escrever. E vingou o disparate e produzio seus bichados fructos, como vamos ver.

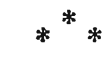

Nos latifundios como nós temos, o occupante ou possuidor pro diviso, que tem condominio, é dono absoluto da parte que occupa, principalmente para os que são extranhos ao predio commum. Elle doa, elle permuta, elle vende, elle aliena sob condição e seu acto é valido e tão valido como si se tractasse de um solo diviso.

Ha só uma relação de direito, que um dia pode-lhe vir tocar nos seus feitos: é a que nasce do condominio, mas essa não pode apparecer sinão em causa communi dividundo. $\mathrm{Na}$ occasião da divisão, dentro de cujo processo se apuram minudenciosamente as forças dos titulos de cada consorte, pode ser o proprietario, que possue pro diviso, obrigado a modificar o seu sitio, terá de sujeitar-se a uma servidão, terá de perder a favor de um confinante um tracto da sua occupação, terá de soffrer uma permuta, terá de compor em dinheiro uma demasia, etc. etc. Mas estas variadas hypotheses não podem emanar sinão de seus condominos e só poderão coagil-o dentro de uma acção com. divid. 


\section{$-33-$}

E como os que são extranhos ao predio commum nada podem mover contra elle, dahi o affirmarmos que, principalmente com os extranhos, o occupante pro diviso é absoluto dono do que occupa.

$$
*^{*} *
$$

A razão natural, e após ella a razão juridica, está mostrando que a Camara Municipal nada tem que ver com o condominio que liga Bernardes VillasBoas aos muitos consortes da fazenda Rio Pardo.

Em I ${ }^{\circ}$ lugar a Camara não fica subrogada a Villas-Boas e seus filhos na posição de condomina.

Ella não fica condomina de ninguem quando desapropria : fical-o-ia si adquirisse por outro titulo.

A fazenda Rio Pardo é que fica diminuida na sua extensão, porque perdeu definitivamente um pedaço que lhe foi soberana e irrectratavelmente cortado e separado.

Mas porque a Camara cortou e fez seu um tracto de terra de um predio commum, deve pagar a todos os communheiros o valor delle?

Não e nunca. A Camara não tem auctoridade e saber para qualificar ninguem de communheiro neste ou naquelle predio. Esse direito só tem reciprocamente os condominos.

E portanto não podia enfileirar uma recova de sujeitos, chamal-os consortes e pretender ratear-lhes o preço do solo que tirou a Villas-Boas.

O poder da Camara e o seu dever é de reconhecer quem é o occupante e si tem titulo de dono. Nada mais. Isso feito, a esse tem de pagar o valor dos bens desapropriados, pois foi a elle que ella privou dos bens que estava fruindo. 
Esse proprietario, ao depois, quando houver acção comuni dividundo, é que se comporá com os seus consortes.

Mas no momento presente, admittido que o preço das terras desapropriadas seja um valor commum a todos os condominos, ainda assim só ao consorte desalojado é que se deve dar o preço, porque esse preço fica em verdade subrogado ao solo que elle perdera. E é contra o senso commum que eu só soffra a perda e tenha entretanto de repartir com meus consortes o dinheiro, subrogado pela lei aos bens de que fui privado.

$$
* * *
$$

Nem se creiam obscuras ou subtis as relações que vinculam de futuro Villas Boas com seus consortes pelo facto de este haver recebido o preço das terras desapropriadas. Claras são ellas e palpaveis. De feito, quando alguem mover a acção com. divid. sobre a fazenda Rio Pardo, tem que figurar na planta e tambem na avaliação o solo que occupava Villas Boas e cujo valor elle recebe da Camara.

Apurados os titulos de cada qual, applica-se ao pagamento do quinhão de Villas Boas o valor que então se der ao terreno desapropriado. Si esse valor bastar a seu pagamento, está bem; si sobrar de seu pagamento, elle repõe ao monte o excesso; si não bastar ao complemento de seu quinhão, terras se lhe darão no valor que falta.

$$
*^{*} *
$$

Ainda uma reflexâo para terminarmos este capitulo. $\mathrm{O}$ acto de desapropriação não está longe, sob 
certo aspecto, do contracto de compra e venda. Ora, o communheiro que vende a sua propriedade não só não tem de consultar a ninguem sobre a suá capacidade de vender, como não tem que dar contas a ninguem do preço que tractou e recebeu.

Imaginemos coisa muito verosimil, e que todos os dias se dá nesta Cidade, que em vez de desapropriar as terras e bemfeitorias de Villas-Boas, a Camara de Botucatú lhe comprasse tudo. Os outros condominos da Fazenda Rio Pardo tinham nada que ver com isso? Nada, absolutamente nada. A Camara pagaria o preço a quem lhe vendeu as terras e bemfeitorias, sem attenção alguma a serem parte de um predio indiviso.

Como, pois, só porque variou a forma da alienação, quer o procurador da Camara que o preço se reparta?

\section{Erros do juizo}

O Meritissimo Juiz a quo, respeitavel sob todos os aspectos, deslizou do terreno plano do direito para o soslaio de um tojal emmaranhado.

O I. ${ }^{\circ}$ mal foi deferir ao desproposito do procurador judicial, que jungio o $\mathrm{Com} .{ }^{\text {dor }}$ Ferreira, que tem sua propriedade fora inteiramente da communhão, aos condominos do Rio Pardo.

Porque, fosse embora verdade que os condominos do Rio Pardo devessem tomar parte neste processo de indemnisação, nem por isso o Com. ${ }^{\text {dor }}$ Ferreira tinha que ver com isto.

A Camara devia chamal.o á parte em seu pro. cesso particular. Mais adiante veremos como se accentua muito mais o absurdo desta junç̧ão mons. truosa. 
O 2. ${ }^{\circ}$ mal foi deferir que se chamassem ao preço da indemnisação todos os condominos do Rio Pardo, quando em cada processo de desapropriação se chama o dono ou donos de cada propriedade.

Neste caso, sendo os campos e mananciaes da cabeceira do Rio Pardo occupados por Villas-Boas e seus filhos, a estes, como representantes dessa unidade agraria, é que competia o direito de nomear um louvado, que com o da Camara desse valor ás terras, ás aguas e ás bemfeitorias.

$\mathrm{O}$ direito que tem o proprietario de nomear o seu louvado é um direito inauferivel. O meritissimo juiz a quo arrancou com visivel damno a Villas-Boas e seus filhos esse direito, quando admittio que viessem em chusma a nomear louvados quantos, com direito ou sem elle, se apresentaram como consortes da fazenda Rio Pardo.

A lei garantio inauferivelmente ao proprietario expropriado o direito de nomear louvado seu. E' tanto mais sagrado este direito, quanto no desaccordo dos dois louvados, o direito de nomear terceiro não é mais das partes, sim do juiz (lei, art. 3).

Para que se torne effectiva esta garantia, isto é para que possa o representante ou dono de cada propriedade proteger efficazmente os seus interesses, não ha outro modo de processar as indemnisações sinão instaurar para cada propriedade ou sitio um processo á parte. Nem de outro modo se póde fazer, nem de outro modo se faz, quer nas desapropriações para vias ferreas, quer nas desapropriações para agua potavel aqui na Capital.

O Egregio Tribunal comprehende qual o atropelo com que se sacrifica o direito da parte com este absurdo processo, de metter de cambulhada gregos 
e troianos. O Commendador Ferreira accommoda-se por exemplo com o prę̧o que deranı os louvados; Villas-Boas e seus filhos não se accommodaram e appellam. Esta appellação, por força de estarem tractados todos os interesses no mesmo processo, prejudica o Commendador Ferreira, que podia estar com o seu dinheiro levantado do deposito.

\section{A louvạ̧ão}

Bastava só a louvação para inquinar de nullo este processo.

De que criterio se servio o Meritissimo Juiz $a$ quo? Não se sabe; ou melhor não seguio criterio algum, porque nenhum havia que seguir. A lei nunca imaginou que um processo de desapropriação tomasse as proporções de um chaos, como é este.

Nos processos de divisão e demarcação o autor ou autores dá um, os réos dão outro. Este é o criterio. Da parte dos autores (si ha mais de um) não se póde admittir divergencia: seria absurdo. Da parte dos réos ha, e quasi sempre ha. Decide-se pela maioria dos votantes.

Mas no processo de indemnisação não ha sinão aquillo que manda a lei : o expropriado dá um, o expropriante outro. Este acto é garantia do direito de propriedade.

No actual processo estabeleceu-se o tumulto. Foi um charivari do qual se sahio o juiz mandando vir nos autos, e não se sabe como é que á fl. 7 I surdem do chaos aquelles dois peritos, que ficam es. colhidos, diz o despacho do juiz, quando quem deve escolher são as partes!! 
Escolhidos pelo Meritissimo Juiz a quo os louvados, elles avaliaram terras e aguas. Não encontraram bemfeitoria que não fosse um rancho coberto de zinco.

Entretanto Villas-Boas e seus filhos tinham ali um retiro, isto é um posto destinado a pastagem e a creação de gado, principalmente destinado á creação de porcos. Não viram os louvados pastos, cercas de arame, curral de porcos e casa do empregado. Aliás na propria planta do engenheiro se faz menção de cercas de arame e os louvados nada enxergaram. Que havia ali um retiro, principalmente destinado á creação de porcos, até o jornal da cidade favoravel á tyrannia da Camara o diz de modo muito claro, em contradicção manifesta com o laudo dos avaliadores. Dicto jornal lançou em rosto a Villas-Boas que mandou de má fé accrescentar os curraes, sabendo que ia a Camara desapropriar.

E' digno de nota o final do laudo dos avaliadores: que nenhum damno soffrem os donos das terras, porque nenhum proveito dali tiravam.

Occultaram por completo que Villas-Boas em vez de criar porcos na séde da lavoura, estabeleceu aquelle retiro, onde havia largueza e brejos para os porcos e ao mesmo tempo era distante das plantações, aonde o gado suino não podia chegar a fazer os damnos de que sãc capazes taes animaes.

\section{O preço depositado}

Mandou o Meritissimo Juiz depositar o preço segundo a inepta e estulta avaliação; e no mesmo despacho mandou que as partes se habilitassem a levantar o preço, segundo o direito de cada um. 
Oh céos! Parece que ha uma geral desorganisação do senso commum.

Habilitarem-se quem? Tambem o Commendador Ferreira? Mas o Commendador tem os alqueires certos, segundo a petição inicial, e o preço tambem certo a tanto por alqueire!

E' manifesto engano! Não se habilita quem desde o principio é o mesmo sujeito com direito certo que as circumstancias não alteraram.

De certo a ordem judicial é para que se habilitem os consortes do Rio Pardo. Vejamos si é.

Si não nos engana a vaidade, deixamos atraz provado á evidencia que o preço da desapropriaçâo se deve dar áquelle a quem se tira a propriedade. Mas, por argumento contra o illustrado Juiz a quo, supponhamos que o preço se deva ratear aos condominos do Rio Pardo segundo a habilitação que se fizer em 60 dias. Ora, si este direito de ratear o preço se funda no condominio, é evidente que a proporção se ha de fazer segundo as forças dos titulos dominicaes de cada um. Apurar os titulos dominicaes de cada consorte só se póde na ação communi dividundo. Em outro qualquer processo é impossivel.

Em verdade, si o Meritissimo Juiz a quo, preșcreveu que em 60 dias se habilitem os interessados, é claro que qualquer delles póde offerecer ao juizo os seus artigos de habilitação.

Supponhamos que o nosso cliente Bernardes Villas-Boas é o primeiro a apresentar artigos de habilitação. Elle comeşará por pedir a exclusão de alguns nomes, que estão figurando de condominos e que não o são (certidão n.). 
Bem se về que estes artigos de habilitação vem a ser um pleito em forma, porque para melhorar a minha quota no preço, tenho o direito de excluir os que não são condominos da fazenda Rio Pardo.

Si eu não pudesse atacar nos artigos a razão e fundamento com que sâo charnados a rateio os meus consortes, mal de mim. Mas, si eu devo atacal-os no seu condominio, não cabe tal ataque nas estreitezas de uns artigos de habilitação. E' claro que cada interessado, desses que foram citados para a louvação, tem o direito de impugnar os artigos. Depois teremos a dilação das provas, razões finaes, sentença, com questðes de alta indagação sobre a capacidade dos titulos dominicaes, um ror de coisas impossivel de se fazer em 60 diąs.

Mas, para que é estarmos laborando no absurdo: digamos a coisa como ella é. A divisão da coisa commum só se faz pela acção com. divid. Si o dinheiro é da communhão (absurdo que suppomos para argumentar) elle não póde ser partido sinão pela aç̧ão com. divid.).

Não será a aç̧ão Souza Lima, proc. instituido para dividir immoveis. Mas será uma aç̧ão com. divid. em que as partes tem necessariamente de discutir seus titulos de dominio, sobre a fazenda de Rio Pardo remontando á origem da communhão, descendo depois a todas as ramificações desse dominio desparzido.

No proc. Souza Lima, na divisão de immoveis, depois de entrarem nos autos os titulos das partes revestidos das formalidades legaes, é ao agrimensor que a lei confia o calculo, por onde se ha de saber a que porção do immovel corresponde a força de cada titulo. 
Neste caso tambem o calculo não póde deixar de ter por base a força patrimonial de cada titulo, para, segundo fôr elle, ser-lhe attribuida uma quota do dinheiro commum.

Quem fará o calculo? O contador do juizo? Duvidamos muito.

Não nos detenhamos, porem, nestes tropeços. Os absurdos se amontoam atropeladamente, que não ha tempo de acalmar o espirito. Perguntemos por fim ao Meritissimo Juiz a quo si Bernardes Villas-Boas, alem de despojado de suas terras, terá de propor uma acção com. divid. para receber talvez uma ninharia do seu dinheiro? Comprehende-se isto como medida que lhe imponha o poder judicial, unica força que resta contra as tyrannias cada dia crescentes do poder publico? E'. isto garantir o direito de propriedade em toda a plenitude?

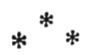

A violencia da occupação. Dizem que o novo regimem foi instituido para termos muita liberdade, egualdade e fraternidade, coisas que não havia no tempo do imperio. A Camara de Botucatú, manobrada pelo Intendente, que faz daquillo um theatrinho de bonecos, entendeu executar com auctoridade propria a sentença do Meritissimo Juiz a quo, que incorporou os terrenos de Villas-Boas e seus filhos ao patrimonio do Municipio.

A tyrannia é em regra o vicio dos homens co. vardes. Foi pela tyrannia que chegou a seus fins a Camara Municipal.

O procurador da Camara, si fosse advogado que prezasse esta nobre qualidade, não teria consentido 
nas correrias barbarescas que ali se fizeram, indignas de uns homens que foram baptisados na lei da Egreja e que tiveram mais ou menos o curso de primeiras lettras.

Vai a licção já talvez sem proveito, mas vá, e Deus o illumine em outra occasião.

Dada a sentença contra Villas-Boas e seus filhos, sentença que obrigava a entregar suas terras á Camara, nem por isso estava a Camara auctorisada a ir tomal-as por suas mãos sem a intervenção da justiça. Tirasse a Camara sua carta de sentença e requeresse a immissão na posse.

Este era o unico caminho: o mais é saltar as raias do direito e fazer papel de selvagem. Citado o dono das terras para ver o juiz immittir na posse dellas a Camara proprietaria, elle viria muito natural e legitimamente com seus embargos de bemfeitorias, que evidentemente seriam recebidos, porque a immissão na posse sendo diligencia feita sobre o local, veria o meritissimo juiz com seus olhos o que não viram os louvados, e veria as cercas de arame farpado, veria o pasto fechado juncto á casa do retiro, veria os curraes para criação e mantença principalmente do gado suino e mandaria que isso se avaliasse e se pagasse (ou fosse depositada a importancia) antes de a Camara metter a mão no que não pagara. $\mathrm{E}$ com isto teria tido tempo o proprietario de retirar com socego os seus gados para não occorrer o que occorreu com tyrannia: a Camara aprehender muitas cabeças de porcos accintosamente e metter no curral do conselho para aggravar os prejuizos do proprietario.

A roda da fortuna é muito varia: e um exemplo detestavel como este, dado por gente de gravata, perturba a noção do respeito á propriedade no animo da multidão; amanhã quem sabe si estes mesmos 
tyrannetes de hoje não soffrerão peiores violencias, nascidas do mau exemplo e acoroçoadas pela impunidade.

\section{Um terreno inutilisado}

Por cima dos mananciaes desapropriados, eleva-se uma serra alcantilada, sobre a qual são as culturas de café.

Entre os terrenos desapropriados e a serra existe um terreno não pequeno, que ficou inutilisado para. os Appellantes pela razão de não ter agua. Esse terreno, grande parte de campo, nãu se presta á criação, porque o gado que se ali puzesse não teria accesso aos mananciaes desapropriados. Uma lavoura que tambem ali se estabelecesse não teria tambem agua nem para beber, nem para o mais serviço domestico.

Neste caso é força que não sirita o expropriado o prejuizo desta propriedade, mas tome-o sobre si a Camara, ficando-se com esse terreno. Com quanto a lei provincial de 1836 não acautelasse a hypothese, ella está perfeitamente acautelada no Dec. n. I664 de 27 de Outubro de 1855, absolutamente applicavel á nossa especie. CARlos dE CARvalho, tractando das desapropriações em geral, estabelece os tres casos principaes em que o proprietario póde requerer a desapropriação do todo, a saber: a) quando flcarem os predios reduzidos a menos de metade de sua extensão; b) quando ficarem sem serventias necessarias para uso e gozo da parte restante; $c$ ) quando ficar muito desmerecida a parte restante por carecer de obras e bemfeitorias. Nova Cons. art. 848, \3. 
Pedimos, pois, ao Egregio Tribunal que se pronuncie sobre este caso, determinando que o Meritissimo Juiz a quo verifique por meio de vistoria, com peritos nomeados pela Camara e pelos expropriados, si realmente o terreno ficou imprestavel para os $\mathrm{ex}^{-}$ propriados, segundo o teor de sua vida agricola; e, si tal for, seja logo avaliado para ser adjudicado á Camara, que pagará o seu preço.

Raphael CorrêA. 